\title{
"Women" Versus "Breadwinners": Exploring Labour Market Dynamics, Agency and Identity Among Migrant Nurses from Kerala (India)
}

\author{
Sumangala Damodaran, Ambedkar University, Delbi, India
}

\begin{abstract}
This paper examines the relationship between migration, the availability of paid work and identity (as workers and as women) of migrant nurses from Kerala, India working in Delhi. It explores the dynamics of labour market formation, autonomy and choice for this group of women who more often than not enjoy primary breadwinner status in their families. It argues that migrant nursing employment provides interesting insights into the way women perceive as well as manoeuvre their positions as workers in their work contexts and as women in their family contexts, in certain cases achieving significant transformations and in other cases reinforcing existing norms.
\end{abstract}

\section{KEYWORDS}

international care chain, Kerala nurses, migration, primary breadwinner

\section{Introduction}

Feminist studies have, for a few decades now, emphasised (Elson and Pearson 1981) the fact that there might not be a one to one correspondence between women's work and empowerment, but at the same time, paid formal work may still act as one of the most crucial factors behind transformation of a woman's life. One of the aspects that has been examined, in the context of the complex relationships between women, employment and family is that of the reconstitution and negotiation of structures of hierarchy through paid employment (Kabeer 2000). How this reconstitution and negotiation takes place in the case of a particular category of women, i.e., migrant nurses from the province of Kerala in South India, is the theme of this paper. ${ }^{1}$

Nursing employment in India is being presented as a case study for analysis of women's work for the following reasons: First, nursing, as a typical example of care work, brings forth specific dimensions of women's work based on a stereotypical gendered division of labour from the specific social context of South Asia and more specifically, Southern India. Here, even as nursing, as care work, is 'typical women's work' on the one hand, it also carries with it typical stigmatizing notions of 'dirty work' due to its association with contact with human bodies, particularly those of unfamiliar 
men, ${ }^{2}$ making it potentially taboo or 'morally degrading' for women in a traditional sense on the other. This has been pointed out in previous work on nursing employment in India (George 2000) and is an important dimension of identity formation that this paper focuses on. Such ideas of stigma are grounded in caste hierarchies in the Indian subcontinent and in turn acquire a gendered dimension through segregation between men and women. In the case of the Malayalee nurses ${ }^{3}$ from Kerala that this paper is based on, the majority of them are Christian, this being an important aspect that helps in de-stigmatising nursing and appealing more to its care aspect, something that will be taken up as a central point in the paper. The broad religious identity of 'Christian' is not being broken up into constituent denominations as they exist and as constituting aspects of sub-religious identity, but to bring attention to the 'care' aspect of nursing work emphasized by Christianity. Hence, the interplay of multiple identities, social, religious and gendered, in enabling the breaking out of the stigmatized associations of nursing, is explored through this case.

Second, nursing employment is a typical example of the high premium attached to women's entry into salaried jobs in the state of Kerala. This, in turn, is historically embedded and has contributed and in turn been reinforced by education of women. This aspect becomes even more significant in the case of nursing work, where employment is guaranteed and examples of families where boys' education takes a backseat compared to that of girls are common.

Third, a major aspect of nursing employment is the nurse's status as primary breadwinner in the family, both before and after marriage, in most cases. A woman who is the primary breadwinner in her family and in the case of migrants, is the solo migrant or the initiator of migration for the family could, because of the dependence of other family members on her income, potentially enjoy greater autonomy in decision making and possibly question structures of hierarchy and the sexual division of labour. In this case, the primary breadwinner status is related to the social background that the nurses from Kerala come from, high rates of unemployment in Kerala and the relatively higher income earned by nurses compared to other family members even in the home state.

Fourth, the premium for salaried employment as nurses and the nature of the primary breadwinner status acquires particularly interesting dimensions when these women are migrants, because their identity as workers, as women and as migrants get intertwined. When work is located away from the community / larger family home, involving a dislocation from familiar contexts and encounters with unfamiliar cultures and people, it can create the basis for construction of a lifestyle or family where a certain autonomy or choice, however delimited, may be available. The possibilities of transformation in the context of waged work and the ability to confront/negotiate structures of hierarchy become more complex as it is not merely their identity as women, but also that as migrants that shapes these.

Fifth, the migration of Malayali nurses from Kerala has acquired transnational dimensions with migrants' ultimate desired destinations typically being the countries of Western Europe and North America. They are thus part of global care chains and their case presents interesting evidence for changes in gendered identities that occur with transnational movement. However, in the case being explored in this paper, that of women who have achieved one level of migration, from their home state of Kerala to the large capital city of Delhi, it also allows us to understand the implications of the desire to migrate abroad, their stated preferences for working in different parts of the world outside India and the attitudes to work in India as a result. In other words, it allows us to understand 
the expectations from migration, something that impacts the labour market for nurses in the home country or home province significantly.

The case of these migrant nurses, because of the above stated features, is an interesting one that allows us to straddle a whole range of situations relating to gender, care work, migration and identity. Some of these aspects have been covered by Percot (2005) and George (2000) specifically with regard to Indian nurses. The particular case of Kerala in terms of education, the premium attached to education in general and women' education and employment in particular have also been the subject of study and debate for a long time now (Zachariah and Irudaya Rajan 2001, Gulati 1997, Kannan 2005), as has the role of religious identity in migration streams (Osella and Osella 2008). This paper takes the case forward by looking at nursing employment as part of the global care chain, which was a concept coined by Hochschild (2000) to refer to 'a series of personal links between people across the globe based on the paid or unpaid work of caring'. Based on previous research about migrant domestic workers in Los Angeles and Rome that was published in 2001 by Parrenas, Hochschild's focus lay with transnational transfers of 'motherly' labour from poor countries to rich countries. By placing nursing within the concept of transnational care chains, this paper looks at the relationship between the need to be placed within the chain on the labour market situation within the country and the influence of this dynamics on questions of identity, selfperception, attitude to work, the potential for perceiving the need for and posing challenges to structures of hierarchy among the nurses interviewed. While Percot (2005) and George (2000) focus on nurses who have migrated to the Gulf countries and the West respectively, this paper focuses on the aspirations for migration by those in the city of Delhi, the different steps that are desired in the migration chain and the effect of all this on expectations from employment. Most importantly it addresses these questions and the women's self-perceptions as women, as migrants and as workers in the context of the primary breadwinner status of most of them.

\section{Kerala Nurses in Delhi-A Brief Profile}

Migration outside Kerala by nurses has been a continuing phenomenon for more than three decades now. In a state where the moral and social codes regarding women's behaviour and sexuality are strong and rigid, large numbers of these women have moved out of their home state to be employed in far flung areas of the country in a job that requires them to interact very closely with the patients that they care for. Across the entire time period that nurses from Kerala have been employed outside the state, they have come to acquire a reputation for being professionally efficient, willing and caring workers. In the last couple of decades or more, this chain of movement from Kerala to other states in India has been extended to the international economy, with large numbers of nurses moving to West Asia and western countries. ${ }^{4}$

A casual examination of the ethnic profile of nurses in a city such as Delhi shows the large proportion of migrant Malayalee women among them. At a preliminary level, it is also seen that the majority of them appear to come from a few districts in the state and also happen to be Christian. This is related to a specific history of women's incorporation into the world of work, especially in a profession which carries a social stigma that is characteristically Indian, or even South Asian. This, in turn, is historically embedded and is related to notions of 'purity' and 'pollution' and their 
associations with particular groups of people and kinds of occupations in the caste hierarchy. Under the Hindu caste system, it has been customary to designate certain occupations and the groups of people practicing those occupations as 'dirty', 'polluting' and 'impure', these typically being cleaning, scavenging and working with flesh and skin, such as leather-making. Combined with a highly gendered social structure, work such as nursing that requires women to have contact with sick and alien men came to acquire connotations of impurity, akin to that associated with the above mentioned kinds of work. Women from respectable families among the Hindu majority communities would not be allowed to consider nursing as a possible profession, even when they were permitted to look for work outside the home. The following extract from a magazine report indicates the persistence in attitudes, although slow change has happened, 'Traditionally, not too many would advertise for a bride nurse. People thought they were dirty as they handled the sick and the poor. Society questioned their chastity as they touched strange men unsupervised. Attitudes haven't completely altered, but things have certainly changed for the Indian nurses, especially those from Kerala. As they get better opportunities in the western nations...and earn more money than many other professions, they have gained success and unexpected leverage' (Outlook 2006).

An exception, as indicated in the report above, was seen in the province of Kerala, with the setting up of Christian missionary institutions for nursing from the early twentieth century, especially in the region from which most nurses come (known as Travancore), where the Church provided the legitimacy for Christian families to send young women outside their homes for training in a profession that symbolised care and service and also provided lucrative avenues for employment within and outside the state (George 2000), thus also facilitating de-stigmatisation. The beginnings of this phenomenon can be traced to the Second World War where Christian women from Kerala were sent with the sanction of the church for army service. Recruitment efforts made by nursing schools set up by them in Kerala were successful from the fifties or so in finding large numbers of students from the different Christian communities. Many nursing schools provided free education and a monthly stipend to the students in return for a stipulated time of bonded service by the nursing graduate after the completion of her education. In the post-Independence period, the large increase in demand for health facilities and within that, for nurses, was met by this supply of nursing personnel from Kerala, as well as from neighbouring states like Tamil Nadu and Karnataka, where Christian institutions have played a key role in producing for these women a sacralised work ethic.

In the post-independence period, the growth of healthcare services in Kerala, which is well known for its developed system of healthcare, resulted in increasing employment opportunities for these nursing graduates who also acquired the reputation for being very well trained, again due to the high quality of the educational institutions run by the missionaries. These employment opportunities soon also came into existence in other parts of the country, providing the opportunity for women to migrate in search of jobs that were relatively easy to come by, compared to the employment opportunities of other members of their families. This resulted in the interesting phenomenon where it became a better strategy for a poor family to invest in a girl's higher education than a boy's due to the greater possibility of finding employment. This is something that makes the experience of Kerala nurses different from that of women from other parts of the country, where it was rare to find families actually spending more on the education of their girl children. In Kerala, 
often it is a family project to scrape up enough money to send a daughter for training to become a nurse, as that provides insurance against uncertainty in a poor household's context.

Along with the high supply of nurses from Kerala, there were significant changes in the labour market for nurses in India, influenced strongly by the growing transnationalisation of nursing labour and their subsequent international migration. The dynamics of multi-stage migration, first from the home province to other provinces in the country and the aspirations to migrate abroad, to the Gulf states and eventually to western countries, created particular conditions in the labour market, which this paper brings forth below.

\section{Methodology}

Between May and mid-October 2005, fieldwork was conducted in two major public hospitals, one big and one small private hospital. The nature of the issues that we were interested in made a formal questionnaire inappropriate for the kind of questions that we needed to ask. This was both because the interviewees felt they would be wasting time on duty by doing so and were also suspicious about how this would be used, whether what they wrote could be used as evidence against them. Given the reluctance to respond in formal ways to our enquiries, we decided to use an open ended conversational mode for interviews. Following Kabeer $(2000)^{5}$, fifty nurses working in four hospitals in Delhi ${ }^{6}$ were selected using a careful snowballing method ${ }^{7}$ and their own accounts of their situations were also elicited through oral testimonies in order to examine the basis for decision making regarding participation in work and their notions of agency and autonomy.

Of the fifty nurses interviewed, one could distinguish between three categories of nurses broadly divided on the basis of age-group. ${ }^{8}$

(1) The first age group of women (twenty in number) between the age of 20 and 25 who were either fresh graduates or those working in their first or second short duration jobs

(2) The second age group of women (twenty in number) between the age of 25 and 40 or so, who are experienced and have worked for many years and who are looking for lucrative overseas jobs.

(3) Senior nurses (ten in number), above the age of 40, who are stable in terms of location and would consider moving only with retirement or if substantially better prospects are available within the city.

Of the fifty, about ten had BSc (Nursing) degrees, a superior qualification to the regular degree that is a Diploma in Nursing, which gave them a better possibility of getting a job overseas, especially in the West. Of these, five also had additional qualifications, like in burns nursing, geriatric nursing and so on. All the nurses, except one, were married, 40 of them had two children each, 7 had one child each and 2 did not have children.

The nature of interaction with the city, the extent to which they integrate with the city's culture, their conceptions of themselves as migrants and as women, were found to crucially depend 
on which above category the nurses belong to. At the same time, there are interesting generalizations on gender that are possible across the categories.

The following sections trace the dynamics of the labour market for nurses from India in India and abroad and investigates questions of self-perception, agency and choice among Malayalee nurses working in Delhi.

\section{Labour Market for Nurses: Migration, Instability and Shortage}

The demand for nurses within India has been a continuously expanding one due to massive increases in health infrastructure in the country. ${ }^{9}$ Along with this demand, there was a huge increase in the number of nursing schools that came into existence over the entire period from the late sixties onwards. In Kerala alone, between 1977 and 1991, the number of nursing schools went up from 26 to 62, of which more than four fifths were in the private sector in 1991(Abraham 2004).

However, even with the availability of trained nurses ${ }^{10}$ being around 700,000 or so in the late nineties, hospitals have functioned with nurse-patient ratios of 1 : 70 or even more which is considered grossly insufficient by international standards which prescribe the ratio to be $1: 5 .{ }^{11}$ Further, state governments and private hospitals are faced with a perpetual problem of shortages due to not being able to fill vacant positions for nurses. A critical aspect governing domestic demand for nurses, thus, is of supply not being able to keep pace with the requirements of the population and there being a perpetual shortage of nurses in spite of the large numbers being trained.

Along with this, the international market for nursing care is an important determinant of how the domestic labour market for nurses has evolved. Like with domestic workers where the global care chain is driven by the fact that women in advanced countries, due to entering paid employment, find themselves unable to fulfil 'domestic duties' of child care and house cleaning and purchase other women's labour, drawn from poor households either locally or from abroad, this is true in nursing as well. ${ }^{12}$ A rich country, to provide high standards of healthcare to its citizens, but without incurring the cost that it would have to pay if it employed its own people, increasingly provides the impetus for the creation of the global nursing chain, involving multiple levels of incorporation between the home province and the ultimate international destination.

Further, severe shortages of nursing personnel in advanced countries have been experienced for several reasons, resulting in a 'care deficit'. One, despite financial incentives for nurses, the culture of nursing has become less appealing to the local population in many countries, with enrolment in nursing schools declining. Two, increasing demands on nurses, partially a result of the shortage of nurses, have led to early career burnout. Three, the nursing shortage is accompanied by high and rising cost of health care in all the advanced countries, making the recruitment of local nurses an expensive affair. Given the availability of nurses from developing countries who cost much less, each country aims to compete for them in a globalised marketplace.

Our interviews showed that the majority of the nurses from Kerala want to get incorporated at some point or the other in this global chain, with the possibility of being able to go to the next level and eventually to a destination in an advanced country. One of the important aspects that emerged in the interviews was that hardly any waiting period was reported in the labour market for fresh graduates, both from within the city and outside, i.e., the nurses found jobs very easily, even if 
not necessarily on the terms that they considered good, reflecting the general shortage. However, they also did not wait to find jobs where the terms of employment were more acceptable to them because of their intention to move on as soon as better opportunities are perceived. While these better opportunities, as and when they were available, would be taken up within the city itself, they very clearly look at this employment as only the first stage towards much more lucrative opportunities abroad.

Interestingly, in the first category of fresh graduates who are mostly unmarried, nurses reported that they would be willing to work in any job abroad, including in West Asia, as it would represent better opportunity. The domestic labour market for nursing, thus is unstable and with very high rates of turnover.

One of the major reasons cited for going abroad is to earn substantially higher salaries, even at the lower levels that those countries themselves paid foreign nurses, in comparison to what their own nurses would need to be paid. The segment of the labour market where nurses are employed at the junior-most level is the most unstable one, with very high rates of turnover. What has been said above was substantiated in terms of a whole range of starting salaries, ranging from 2500 rupees a month (less than the stipulated minimum wage for unskilled workers at the time) in a small private nursing home, to 10000 rupees a month in a larger, public one. It was the fact that they were hopeful about getting better paying jobs outside the country that allowed them to put up with difficult conditions even with small salaries.

This aspect came out even more starkly with the next age group, who were mostly married ${ }^{13}$ and were in the process of arranging dowries for younger women in their natal or marital families. These are nurses with a fair amount of work experience, working in fairly stable jobs, moving in response to significantly better opportunities, such as the ones available in Western countries. They are women who have been in the city for more than five years and are mostly married with families living in Delhi where they are the primary breadwinners. Of the women interviewed in this category about 20 percent were working in government hospitals with the rest in private hospitals. Seven of them had worked for some time in Kerala and eight had worked in the Gulf countries of West Asia before moving to Delhi, and the rest started their careers in Delhi. The Gulf returnees reported a lack of freedom and a complete lack of social life as reasons for returning from the Gulf, as a result of which they did not seek to extend contracts. The nurses who left jobs in Kerala reported low salaries, low nurse-patient ratios and more difficult working conditions as reasons for moving away from Kerala. For those who found government jobs in Delhi, the conditions of employment were reported as highly satisfactory in terms of remuneration. They felt their situation was good compared to the private sector, but were also on the lookout to migrate to Western countries. While they considered their present salaries good in comparison to that earned by others in their families here and back in Kerala and also to that in the private sector, they argued that in an expensive city such as Delhi, their salaries would not allow them to save anything substantial for different needs. These needs are primarily buying property back at home in Kerala and paying for the marriage and dowry expenses of younger women in the family.

In the third category of nurses, the senior ones, they reported that they did not enter the race for jobs in the west, with change being envisaged only if it is substantially more lucrative than their present employment. This is also reflected in hardly any rhetoric on freedom and mobility from 
women in this category. This is illuminated most clearly in the case of those working in government hospitals. While many considered alternatives only as post-retirement options, others felt that a good salary in a private hospital might be an incentive for moving because of the possible lower workload. In keeping with their age profiles, these senior nurses' relative stability with respect to the city was related to husbands having stable jobs, themselves having stable, well-paying jobs and having children who had grown up entirely in Delhi and therefore developing a sense of identity with the city. These migrants do not want to go back to Kerala even after they retire and identify themselves as Delhiites more substantially. Nursing employment in India is thus a phenomenon closely linked to international migration patterns, this being a relatively new phenomenon going back to just over a decade or so. In other words, while women from Kerala have been migrating abroad from the late sixties, the fact of the majority of nurses being interested in looking for jobs abroad is related to the increases in employment of nurses from countries like India. Given the experience of single women migrating out of their home contexts being common, these women find it relatively easy to cope with the different aspects of migration that are implied in international migration. So issues such as lack of freedom and social mobility in West Asia are not serious enough issues for the first age group whose primary prospects for work abroad are in the gulf countries. For the second category, the status of being married and experienced makes them more choosy about where they would like to migrate to, but even here, their experience of migration from a very young age and from a context where it is not a strange thing for women to migrate makes them open to negotiating the particular problems that arise with migration. So both from a demand and supply side, it is the international conditions of migration that determine the conditions in the domestic labour market for nurses in Delhi. It also needs to be emphasized that this is a relatively new phenomenon, barely a decade old, where patterns of nursing employment in the city are conditioned to a large extent by the demand in the international market.

\section{Nurse as Breadwinner: Agency, Roles and Responsibilities}

Most of the nurses from Kerala and also the ones that were interviewed fall under the primary breadwinner category and this is related to the backgrounds that they come from. In most cases, nurses come from farmer/ clerical government employee kinds of backgrounds ${ }^{14}$ and are clearly not affluent. While most of them do not belong to 'poor' families, their backgrounds would at most be lower middle class, where it is necessary for children to look for employment as soon as they can and they would be educated at most to the secondary school or undergraduate degree stage. In the case of the men in the nurses' families, most did not have more than an undergraduate degree. The possibility for these men of finding and being engaged in jobs that would allow them more than a lower middle class existence is low.

In the case of unmarried girls, they are considered the most eligible in terms of future employment opportunities within their families even if their current incomes are not very high and in the case of married women, most of the husbands are employed in more vulnerable conditions than them and earn less. The primary breadwinner status of nurses thus gets generated because of the

social strata that nurses come from and because men from the same families and backgrounds are almost always less 'employable' than them. 
Further, individual testimonies also confirmed the premium attached to women's employment as nurses and nursing education as an opportunity to spread risks for vulnerable families in Kerala, a phenomenon that has got exacerbated due to the uncertainties associated with its economic structure. ${ }^{15}$

The primary breadwinner status of the nurses due to high unemployment among males and high possibilities of superior employment for nurses is reflected in particular kinds of family strategies. Decisions are made in families not with regard to whether they will work, but how soon they can start work and how a better job can be obtained. Once a migrant, a typical nurse's status as primary breadwinner gets enhanced with greater mobility, also because it is rarely that husbands' jobs improve with the movement. Families are thus extremely active in the search for better employment for the nurses. The primary breadwinner status involves responsibilities towards families in terms of meeting consumption needs of all family members both in the location of migration as well as back home in Kerala and financing of long term needs of the entire family that include secular changes in lifestyle in line with trends in Kerala. These needs range from buying/constructing a house in Delhi or in Kerala, supporting younger siblings, mobilizing money for paying dowries of younger sisters on their or the husband's side, and having enough money to buy gifts for family back home when they go home on vacation. ${ }^{16}$ It was made very clear that with a nurse in the family, the family would absolve itself of any responsibility to mobilize money for their marriage or for that of any non-nurse sisters.

How do migrant nurses perceive their role as primary breadwinners? Does it give them greater control over their income and allow them greater agency of decisions? In the case of the fresh graduates or the first group of those interviewed, it was seen that there was a major premium on salaried employment in all their families and working to be away from their families was a preferred option and a strong feeling that they expressed even if their own sisters or brothers, families were in the city. They uniformly expressed a sense of liberation at being away from families in Kerala and being able to live 'as they wanted'.

When questioned about what they considered restrictions on living 'as they wanted', they talked about being able to go out when and where they wanted, not having restrictions on timings, having control of their incomes, and so on but when we enquired more deeply into the actual freedom that they had, we found that it had more to do with mobility in a physical sense rather than actual freedom in terms of control over income. In fact, we found that even when they had members of extended family (sisters, aunts) living in the city, they stayed with them only for the first few months after they moved to Delhi and moved out with their friends as soon as it was feasible. One of the respondents, Alice, who had an older sister in Delhi who had brought her to the city, moved out a month after she got a job that paid her only 2500 rupees per month, grossly insufficient for a decent standard of living. However, she decided to move in with three friends to a small one room, cramped dwelling because she wanted to be able to wander about with her friends after her hospital duties, without having to report to family about where she had gone. 'Isn't it great freedom to be able to come back home at any time, to hang around the shops, even if you can't buy anything? If I stay with my sister, my brother-in-law will be breathing down my neck and won't allow me to go out after dark', she said. Apart from reflecting the sister's or brother-in-law's desire to control her, it also seems to indicate a desire to not confirm to codified norms of behavior, including sexual 
behaviour, although the public stance of the group as a whole would be to be seen to follow codes of behavior.

The 'freedom away from family' was expressed very concretely even by the second group of mostly married, experienced nurses who stated that moving out of joint family contexts to nuclear families consisting of them, their husbands and children was 'liberating' in terms of not having to cope with day to day demands of the extended family. 'My mother-in-law will demand a daily share of my earnings if I live with her, which I will have to if I work in Kerala', said one of them. Almost all of them did not want to return to Kerala when they retired and the fact of being away from the joint family context was cited as the major reason. However, it did not mean a larger control over their earnings because of the extent of responsibilities.

What is interesting is that while it means almost unending demands by the whole family, it is a major source of satisfaction among the nurses from Kerala and is seen as a big contribution that they make towards their family's well-being and they are clearly proud of their ability to do so. We were told by one of the nurses we interviewed at one of the large public sector hospitals that a dowry of two hundred thousand rupees was settled for her own marriage; this was paid up as seventy-five thousand rupees in cash and the rest in the form of gold jewelry. This was possible because her older sister worked as a nurse in Saudi Arabia and generated one hundred thousand rupees. Another nurse was able, along with her husband's earnings, to settle respectable dowries for two of her sisters-inlaw. The senior nurse we interviewed at the private hospital in East Delhi cited very proudly the example of her sister's two daughters who are both nurses and are in Saudi Arabia. She observed that although life in Saudi Arabia was tough for the girls, they would be able to earn handsome dowries and secure good marriages for themselves and free their parents from the burden of arranging huge dowries. One of the senior nurses we interviewed at one of the smaller hospitals, Elsie, told us that she earned her dowry which was a grand twenty tolas ${ }^{17}$ of gold, in fact she reported to us very proudly that all the girls from Kerala who become nurses succeed in doing this. 'We convert any earning in excess of essential expenditures into gold', she said, 'unlike women from this part of the country who buy lipstick and fancy clothes. We do not believe in wasting our money on trivial feminine purchases, we want to use it for the good of our families and since we are lucky enough to be able to get good jobs, we do it'. In fact, she lamented that she was not able to wear some of that gold regularly to work because she came home at odd hours at night and in an unsafe city like Delhi, she was worried about being attacked and robbed.

This repeated assertion raises important questions about the emancipatory potential of wage work and reveals a completely different understanding of the notion of agency. It is clear that most among this group of well-educated and skilled professionals are quite content to accept the norms of a conventional patriarchal marriage with its excessive dowry requirements, and are proud of their 'usefulness' often only to facilitate the dowry and marriage of another woman in the family. There is hardly any reluctance or even an attempt to question or disregard the practice of dowry, it is almost accepted as a natural fact of life.

This preoccupation with dowry among the nurses from Kerala is reflective of intensifying dowry trends in India, documented by several studies on the subject (Anderson 2003, Rao 1993, Percot 2005, and Deolalikar and Rao 1998), which show that dowry inflation has occurred and persisted despite its illegal standing. ${ }^{18}$ In addition to real dowry inflation, the custom of dowry 
payments has spread geographically and socially throughout India into regions and communities in which it was never practiced before. Further, with a growth in economic well-being, dowry payments tend to go up and that is what gets reflected when the burden of dowry payment falls on the primary breadwinner, in our case, the nurses. In this particular case, their ability to fend for themselves, pay their own dowries as well as that of younger sisters and sisters-in-law, goes to enhance their prestige and reinforce their status as primary breadwinners. Of course, this happens also because in South Asian communities in general, marriage of all female children is an unavoidable imperative imposed exogenously on all families (Rajaraman 1983).

However, as is clear from the above, it cannot be argued that wage employment and migration leave the patriarchal norm unchanged for nurses or that they do not try to negotiate around the prevailing norms. In fact, their 'bargain with patriarchy' to use Kandiyoti's (1988) phrase ${ }^{19}$ is in terms of moving away from a joint family context to a nuclear family one, facilitated by the possibilities of migration and the accompanying enhanced earning potential. This move allows them to renegotiate family life in ways that would have been unthinkable for them back at home.

These findings led to a series of further questions relating to the relationship between women's identity as workers and that as women. How does the perception of themselves as women influence their assessment of the transformatory potential of waged work? In what ways is this influenced by their identity as migrants? Do cultural factors and perceived gender roles circumscribe the degree to which these women expect and experience transformation in their lives? The next section summarises the salient findings with regard to how migrant nurses from Kerala see themselves as women and as primary breadwinners.

\section{Gender and Identity in Migrant Nursing Work}

The specific questions in the interviews had to do with how they perceive their work as nurses in relation to society's perception, how they look at themselves as women in a different cultural context, how they balance their responsibilities as wives and daughters between home and work, how conflicts are resolved when they arise, and so on. The interviews revealed that nurses' perception of their work consisted of great pride in the level of education that they had obtained, especially in comparison to their family members, or in comparison with non-Malayalee women in Delhi from similar social backgrounds. 'You know how important it is for everyone in Kerala to go not only to school, but also to college and to study science', said one of them whose father is a farmer in Kerala. 'Nursing is not like any other job for women because we have to do well in Physics, Chemistry and Biology at the pre-degree (intermediate) level to get admission into nursing. In fact, we have to study almost as much as the doctors do about the human body and diseases'. This view represented that of the nurses with better jobs and more experience although the pride in educational achievement was uniform.

Across the board, this perception is also combined with a sense of not doing just another job but a noble one. This is clearly connected with the Christian service ethos that is consciously nurtured with respect to work in medical institutions. ${ }^{20}$ The Christian ethic of noble service informed self-perception of nursing work by nurses from Kerala to a very large extent even when 
other communities have now entered the profession in large numbers and many of them have been educated and trained in non-Christian institutions. All the interviewees emphasised the fact that they went to Church regularly, that this was one of the major community activities around which socialising took place.

The pride in their work is also related to the possibilities of superior employment prospects compared to others from their social backgrounds which, as it has been seen, is related to the conditions of demand for nurses. Further, the actual conditions of employment in Western countries, which is what most of them want to achieve, are far less arduous than those prevailing in India, apart from offering substantially better terms of remuneration, even if cheap by those countries' standards. With migration, the primary breadwinner status gets enhanced, as mentioned earlier, because husbands rarely find jobs that are even remotely as good as that of their wives.

It may also be argued that nurses' pride in their work is something that needs reinforcement in order to counter conservative societal perceptions regarding possibilities of nursing work. In response to the question of whether there was a societal perception of nursing work being dirty work due to its association with having to deal with 'bodies of men', there were two types of responses. One set of people argued that this perception arose from the fact that initially since it was largely girls from needy families who went into nursing, their willingness to go far away from their families might have fed the idea that they were willing to do 'anything' for money although this idea was wholly untrue. It was certainly not true, they argued, in more recent times as women from diverse backgrounds and respectable families had entered the profession, making even an imaginary argument unsustainable. The other argument was that even if there were such perceptions, people who did so would soon realize that nurses would, least of all, yield to 'temptations of the wrong type' because of the noble nature of their work. An often repeated assertion was, 'Our work allows people's wounds to heal, for them to get well, so why should we mind even if it is working with blood and bodies', reflecting a continuous anxiety about the stigma attached to nursing in Indian society.

The other aspect of perception regarding their work was that of it being very difficult on the one hand and of that having no time for distractions as a result of this. In this, the nurses that were interviewed distinguished themselves from non-Malayalee nurses on the one hand and from nonnurses on the other. Nursing, due to the nature of duties and the responsibility it implied, meant that time was at a premium and that free time had to be devoted to the family to make up for odd duty hours. Within the work place, they argued that Malayalee nurses get burdened with most of the work due to their diligence and lack of distraction. This was not merely self-perception on behalf of the interviewees. The senior staff from non-Malayalee backgrounds acknowledged this as a major factor reinforcing the nature of demand for Malayalee nurses. The expression of this aspect came across in interesting ways. Their nuclear family status and not having to live with parents-in-law was clearly stated as a boon for them and it was repeatedly asserted that they did not have the time, the need or the inclination to discuss and gossip about mothers-in-law and sisters-in law like local nurses. Further, they emphasized that they were not bothered about drawing attention to themselves by wearing 'loud lipstick like those from Delhi' and that Malayalees were not interested in being fashionable. 
Some of them said that it had been difficult for them to find men in the arranged marriage set up, but this was something that was changing, especially given the expansion of work opportunities for nurses in Western countries and the possible higher standards of living that marriage to nurses could provide to men. However, almost without exception, it is lesser educated men who marry them. Why do nurses and their families not look for 'superior' husbands with better jobs as would be the case with better educated women in many contexts?

It is here that the testimonies revealed that fact of having superior employment conditions needs to be 'balanced' with a non-assertion of superiority within the home, reflected in nurses' attitudes to men doing housework. The nature of nursing work, with odd duty hours and the fact of being away from joint families meant that husbands had to share responsibilities for childcare and taking care of the home, which would have been done in a joint family by a mother or mother-inlaw. It was repeatedly asserted that husbands had to share housework because it was not possible for the women to do everything before she left for work, as they kept odd hours due to changing duties in the hospitals. They maintained that they would have not needed to 'burden' the husband with housework if they had 'regular office jobs' and the anxiety to get back home and relieve husbands of their 'burdens' was therefore very apparent while the interviews were being conducted. Interestingly, most of the women whose husbands shared in the housework said that they did so only in Delhi and when there was no other woman in the house like a sister-in-law or mother-in-law. In fact, it was emphasised that the husbands took care to not let their own mothers ever know that they shared their wives' household responsibilities. In other words, the potential loss of masculinity for the husbands due to having to do housework was clearly something that caused anxiety that had to be 'hidden' from other family members, especially mothers. All these assertions were made with a sense of superiority about being 'good Malayalee women'. It is clear that the migrant's identity is critical to their perceptions about themselves and is invoked constantly in a situation where their independence from joint families and the freedom that it clearly brings might become a threat to known intrafamily hierarchies.

It is also invoked constantly to justify a lack of integration with the city's culture. As far as the environment away from work was concerned, on the one hand, they considered having a job in a completely different place from home as liberating from a restrictive environment of having to live with family, share income at a day to day level and face restrictions on mobility. On the other hand, this liberation did not mean an integration with Delhi's ethos or with the non-Malayalee population. Thus, the women, cutting across the age groups, made it clear that while they were happy to be away from Kerala, their cultural identity as Malayalees was crucial to their identity and the degree to which they would do things differently in Delhi was circumscribed (voluntarily) by the need for acceptability within the community. Their perception of Kerala as a 'restrictive' place sat very comfortably with their lack of acceptability of Delhi as their city.

On the basis of the above, what can be deduced about the relationship between migration, work and identity in the case of the primary breadwinner nurses from Kerala? Does migrant nursing employment result in greater agency and present an enlargement of choices as far as these women are concerned? To what extent can we see negotiation in gender roles with this kind of paid employment? The following section puts together the major conclusions of the paper and attempts to answer these questions. 


\section{Summing Up - Migration, Work and Identity in Nursing Work}

This paper has examined the interplay between nursing work, gender and ethnic identity on the one hand and the relationship between employment, migration and agency of nurses belonging to the province of Kerala in southern India on the other. In the first aspect, what has been focused upon is the conflict between the ideas of nursing work as 'care work' and 'dirty work' that gets played out in the case of the Malayalee nurses that we have studied. We argue, as Sheba George (2000) and Percot (2005) have done, that nursing work is associated with stigma in the Indian context, despite the Church's valorization of nursing as care work, allowing women from Kerala to enter the profession in large numbers. We demonstrate this conflict through testimonies of nurses, where it can be seen that they are constantly focusing on and choosing to emphasise the noble nature of their work, something that does not necessarily happen with other forms of gendered work.

The second aspect has been explored through examining the aspirations from migration, the preferences for employment in the global nursing chain and the resulting instability in the domestic nursing labor market on the one hand and the dynamics of the primary breadwinner status that migrant nurses hold on the other. We demonstrate the premium attached to women's entry into salaried jobs in Kerala as a result of the high demand for nurses, the associated high priority for girl children's education, something that has the potential to change gender dynamics. Nursing employment is thus 'preferred' employment in both demand and supply terms, which explains the ease with which migration takes place and the aspirations of those who become nurses. We argue that the premium for salaried employment as nurses and the nature of the primary breadwinner status acquires particularly interesting dimensions when these women are migrants, because their identity as worker and identity as migrant get intertwined. Migration often involves a move away from joint family structures to the nuclear family and singlehood, this offering substantially greater freedom from family obligations and greater agency and control over their income on a day to day basis. Similarly, the main breadwinner status of large numbers of nurses is integral to their identity, i.e., decisions are made in families not with regard to whether they will work, but how soon they can start work and how a better job can be obtained. What this paper shows is that the role as breadwinner and therefore having particular kinds of agency is constantly being balanced by their role as women. Women take particular care to ensure that their employment constituted as little threat as possible to the established way of doing things in the family and conforming to the norms set by the community. In the case of the Malayalee women that this paper focuses on, there is an adherence to strictly 'codified' norms of behaviour that reflect a set of values from the home state, rather than that of the destination, these codes in turn reinforcing gender stereotypes. Of course, this does not preclude violations of these norms or the desire to do so, as the rhetoric of 'freedom' often from the youngest nurses, seemed to indicate, but only indicates a public stance of following codified behaviour.

Nursing employment in India thus provides interesting insights into the way women perceive as well as manoeuvre their positions, in certain cases achieving significant transformations in their situations and in other cases reinforcing accepted norms. We might argue that the breaking out of joint family structures and moving to a new place in a nuclear family context offered, in the context of nursing employment, a scope for renegotiation of gender roles within the family and a questioning of practices such as dowry. However, migrant communities tend to reinforce and 
reconstitute family and gender relations through a relatively greater emphasis on ethnic identities. In this case, the identity as Malayalees appeared to dominate the identity as women and the need to emphasise the former tended to circumscribe the possibilities of introspection or questioning regarding the latter.

\section{NOTES}

1. This paper came out of a project on the relationship between Migration and Wage Employment of Nurses conducted by the author and a colleague, Krishna Menon, from Lady Shri Ram College, at the V.V.Giri National Labour Institute, NOIDA, India between March 2005 and January 2006.

2. When work on this project was initiated, something that brought this aspect out starkly was the fact that when we began to search the internet for material on Kerala nurses, some of the first websites that were listed were pornographic sites.

3. This refers to their identity as speakers of Malayalam, the main language spoken by those belonging to Kerala. One of the most common impressions that one gets when one enters a major hospital in Delhi is that of nursing being dominated by Malayalees in large numbers speaking to each other in Malayalam even as they conduct business briskly and converse comfortably in Hindi, the dominant local language.

4. The Times of India, a prominent Indian newspaper, in a report published on 19 January 2005, reported that a U.S. recruiter who directs Nurses for International Cooperative Exchange (NICE) stated that nurses can earn $\$ 50,000$ per year in the U.S. and that the migration of Indian nurses is a marriage between excellent (Indian) nursing schools and an advanced medical system in the US.

5. Kabeer (2000) emphasized the valuable role that personal testimonies can play in uncovering the factors that determine labour market participation by women. By laying emphasis on personal testimonies, she argues that women are not merely passive actors who follow the larger designs set by macroeconomic processes but display substantial agency in decisions, even if it is to reinforce stereotypes.

6. The public hospitals were All India Institute of Medical Sciences and Safdarjung Hospital in South Delhi. Moolchand Hospital in South Delhi was the large private hospital and Red Cross Hospital in East Delhi the small private one.

7. The initial entry into the hospital had to be through a contact in the community, established in each of the locations, who told one of the potential interviewees that we were interested in talking to them about their work. This person, in turn, introduced us to others. 
8. Age group was taken as the basis on which to understand similarities and differences because the priorities of these groups brought out clearly their expectations from employment and migration.

9. This growth was most apparent for public sector medical institutions between 1971 and 1981 and for private sector institutions later. Of the total number of 18218 or so hospitals in the country in 2000, it was estimated that 75 percent were in the private sector. (Deogaonkar 2004).

10. This refers to the category called General Nurse and Midwife, which represents the target group of the study that formed the basis for this paper. The information is from Health Information of India (2000).

11. This figure is for JJ Hospital, one of the prominent private hospitals in Mumbai.

12. Gamburd (2000) and Parrenas (2001) are examples of studies on domestic work that look intensively at the care chain and question of identity and agency of Sri Lankan and Filipina domestic workers respectively.

13. Only one nurse in our sample was unmarried.

14. The sample was relatively evenly distributed between farming, clerical service and small trading backgrounds.

15. Numerous studies (Jeffrey 1992, Kannan 2005, Zachariah and Irudaya Rajan 2004, among many) have underlined the achievements as well as the contradictions of the 'Kerala model' of development, of which a major aspect is that of high unemployment and large incidence of migration.

16. The expectations from a migrant are very high, given that a significant number of migrants send back substantial remittances, which in turn has fuelled a construction and consumption boom in the state.

17. A tola consists of ten grams of gold.

18. Political mobilisation against dowry and the fact of alarming escalation of dowry payments culminated in the passage of the Dowry Prohibition Act in 1961, which outlawed the practice.

19. Kandiyoti (1988) argues that the nature of gender ideology in different contexts is determined by 'patriarchal bargains' that can lead to areas of struggle and renegotiation of the relations between genders. 
20. Their dedication to their work was obvious when we went for the interviews and it was difficult to get them to speak to us because they were being called to wards and rooms continuously. When they were not being able to attend to the patient, it was because there were too many demands.

\section{REFERENCES}

Abraham, B. (2004) 'Women Nurses and the Notion of Their "Empowerment", Discussion Paper No. 88, Kerala Research Programme on Local Level Development, Centre for Development Studies, Thiruvananthapuram.

Anderson, S. (2003) 'Why Dowry Payments Declined with Modernization in Europe But are Rising in India', Journal of Political Economy 111(2): 269-310.

Arizpe, L. and Aranda, J. (1981) 'The "Comparative Advantages" of Women's Disadvantages: Women Workers in the Strawberry Export Agribusiness in Mexico”, Signs 7(2): 453-473.

Banerjee, N. (2003) 'The Marginal Families' in M. Pernau, I. Ahmad and H. Reifeld (eds) Family and Gender - Changing Values in Germany and India (pp. 278-295). New Delhi: Sage.

Centre for Development Studies (2006) Human Development Report-Kerala. State Planning Board, Thiruvananthapuram.

Centre for Development Studies - United Nations (1975) 'Poverty, Unemployment and Development: Case Study of Selected Issues with Reference to Kerala', Department of Economic and Social Affairs, United Nations.

Deogaonkar, M. (2004) 'Socio-economic Inequality and its Effect on Healthcare Delivery in India: Inequality and Healthcare', Electronic Journal of Sociology. Available at: http:// www. healingfoundation.in.

Deolalikar, A B., and Rao, V. (1998) "The Demand For Bride Characteristics And Dowry In Marriage: Empirical Estimates For Rural South India”, available at: http://ideas.repec.org/p/udb/wpaper/90-22.html, University of Washington, Department of Economics. [Accessed 31 March 2011]

Elson, D. and Pearson, R. (1984) 'The Subordination of Women and the Internationalization of Factory Production', in K. Young et al. (eds), Of Marriage and the Market: Women's Subordination in International Perspective (pp. 18-40). London: Routledge and Kegan Paul. 
Gamburd, M.R (2000) The Kitchen Spoon's Handle: Transnationalism and Sri Lanka's Migrant Housemaids. Ithaca and London: Sage.

George, K.K. (1993) 'Limits to Kerala Model of Development', Monograph Series, Centre for Development Studies, Thiruvananthapuram.

Government of India (2000) Health Information of India. Central Bureau of Health Intelligence, Directorate of Health Services, Ministry of Health and Family Welfare, New Delhi.

George, S. (2000) 'Dirty Nurses and Men Who Play: Gender and Class in Transnational Migration', in M. Burawoy et al (eds), Global Ethnography - Forces, Connection and Imaginations in a Postmodern World (pp. 144-174). Berkeley: University of California Press.

Gulati, L. (1997) 'Social Consequences of International Migration: Case Studies of Women Left Behind' in K.C. Zachariah and I. Rajan (eds), Kerala's Demographic Transition (pp. 330350). New Delhi: Sage.

Hondagneu-Sotelo, P. and Cranford, C. (1999) 'Gender and Migration', in J.S. Chafetz (ed) Handbook of the Sociology of Gender (pp. 105-126). New York: Plenum Publishers.

Hochschild, A.R. (2000) 'Global Care Chains and Emotional Surplus Value', in W. Hutton and A. Giddens (eds), On The Edge: Living with Global Capitalism (pp. 131). London: Jonathan Cape.

Jeffrey, R. (1992) Politics, Women and Wellbeing: How Kerala Became a Model. London: Macmillan, New Delhi: Oxford University Press.

Kabeer, N. (2000) The Power to Choose: Bangladeshi Women and Labour Market Decisions. London and Dhaka: Verso.

Kandiyoti, D. (1988) 'Bargaining with Patriarchy', Gender and Society 2(3): 274-290.

Kannan, K.P. (2005) 'Kerala's Turnaround in Growth: Role of Social Development, Remittances and Reform', Economic and Political Weekly, 5 February.

Mazumdar, S. (2005) 'Female Labour Force Participation in Kerala: Problems and Prospects', seminar paper submitted for partial fulfillment of the Master in Population Studies, Centre for Development Studies, Trivandrum.

Osella, F. and Osella, C. (2003) 'Migration, Money and Masculinity in Kerala', Journal of the Royal Anthropological Institute 6(1): 117-133. 
Osella, F. and Osella, C. (2008) 'Nuancing the Migrant Experience: Perspectives from Kerala, South India' in S. Koshy and R. Radhakrishnan (eds), Transnational South Asians - The Making of a Neo-Diaspora (pp. 146-178). Oxford: Oxford University Press.

Parrenas, R.S. (2001) Servants of Globalization: Women, Migration, and Domestic Work. Stanford: Stanford University Press.

Percot, M. (2005) 'Indian Nurses in the Gulf: Two Generations of Female Migration', paper presented at the Sixth Mediterranean Social and Political Research Meeting of the Mediterranean Programme of the Robert Schuman Centre for Advanced Studies at the European University Institute, Montecatini Terme, 20 March 2005.

Rajaraman, I. (1983) 'Economics of Bride-Price and Dowry', Economic and Political Weekly 18(8): 275-279.

Rao, V. (1993) 'Dowry "Inflation” in Rural India: A Statistical Investigation', Population Studies 47: 283-93.

Saradamoni, K. (1995) 'Crisis in the Fishing Industry and Women's Migration: The Case of Kerala', in S. Sandbergen(ed), Women and Seasonal Labour Migration (pp. 124-145). New Delhi: Sage.

Sweetman, C. (ed) (1998). Gender and Migration. Oxfam Migration Series, volume 5. Oxford: Berghahn Books.

Tharamangalam, J. (1998) 'The Perils of Social Development without Economic Growth: The Development Debacle of Kerala, India', Bulletin of Concerned Asian Scholars 30(1): 23-34.

Zachariah, K.C. and Irudaya Rajan, S. (eds) (1997) Kerala's Demographic Transition. New Delhi: Sage.

Zachariah, K.C. and Irudaya Rajan, S. (2001) 'Gender Dimensions of Migration in Kerala: Macro and Micro Evidence', Asia-Pacific Population Journal 16(3): 47-70.

Irudaya Rajan, S. (2004) 'From Kerala to the Gulf: Impacts of Labor Migration', Asia and Pacific Migration Journal 13(4): 497-509. 


\section{BIOGRAPHICAL NOTE}

SUMANGALA DAMODARAN is an economist in the School of Development Studies at Ambedkar University, Delhi, India. She has had a long teaching career in Delhi University and has also been a consultant with the National Commission for Enterprises in the Unorganised Sector (the Arjun Sengupta Committee) of the Government of India for over a year in 2008-09. She has been involved in research and consultation with the International Labour Organisation (ILO) for about a decade now and has worked in a variety of the ILO's projects, on areas ranging from the urban informal sector to Factory Improvement Programmes, Labour Processes and Decent Work. Since 2009, she has been part of the ILO's network called Regulating for Decent Work (RDW). In the past few years, Dr. Damodaran has been involved in collaborative work with the Labour and Livelihoods Unit of the Department of Sociology, University of Cape Town, South Africa. She has been involved in an advisory capacity and in training programmes of the V.V. Giri National Labour Institute, Noida and the National Judicial Academy, Bhopal in India. [email: sumangaladamodaran@gmail.com] 